Check for updates

The BMJ

Cite this as: BMJ 2021;375:n2572 http://dx.doi.org/10.1136/bmj.n2572 Published: 20 October 2021

\title{
Covid-19: UK needs more doctors to support post-pandemic recovery, say leaders
}

Gareth lacobucci

The UK must train more doctors to support the post-pandemic recovery of services, England's national medical director has told MPs.

Giving evidence to the Health and Social Care Committee on 19 October, Stephen Powis highlighted that the UK had fewer doctors per head of population than many comparable nations and that increasing this number was fundamental to tackling the treatment backlog.

"We do need more doctors," he said. "The UK has 2.8 doctors per 100000 of the population including GPs; the European average is 3.7, [the] OECD average is 3.5. Having said that, it's a long time from medical school to becoming a consultant. So, it's not just about extra doctors in the short term, it's around extra clinical staff across the board. And of course, we need to ensure that people don't leave the health service."

Powis acknowledged that the $25 \%$ increase in medical student places announced in $2016^{1}$ would see 3000 additional registered doctors coming through in 2026-27, but he added, "I do think there is a case for increasing the number of medical school placements further."

\section{Training and supply}

This week the Medical Schools Council, which represents UK medical schools, published a position paper ${ }^{2}$ recommending a 5000 increase in the number of medical students, which would equate to 14500 doctors graduating each year. Both the Royal College of Psychiatrists ${ }^{3}$ and the Royal College of Physicians ${ }^{4}$ have previously called for the number of medical school places to be doubled.

Malcolm Reed, co-chair of the Medical Schools Council, said, "Even before the pandemic, it was evident that the medical workforce is not growing sufficiently to meet the demands of an ageing population with increasing comorbidities. The pandemic has only worsened the backlog of care. Without a planned and funded approach, we are storing up problems for future patients, who will not get the care they need or deserve."

In his evidence to MPs, Powis said it was "absolutely critical” that Health Education England's budget was not cut or frozen in the government's spending review next week, as this would undermine its ability to train more clinical staff.

He warned, "The training and the supply of future clinicians is really critical, and it's really important that we have our mind on the medium and the long term, as well as the short term, because unless we get that supply right, then we will be in this perpetual circle of worrying about the future workforce."
NHS England's chief executive, Amanda Pritchard, also giving evidence to the committee, echoed this view. "From our point of view, anything that we can do that gives us greater predictability around the future of the training and supply side on the workforce would be hugely beneficial," she said.

1 Torjesen I. Hunt aims for fully home grown doctor workforce. BMJ 2016;355:15399. doi: 10.1136/bmj.i5399 pmid: 27702756

2 Medical Schools Council. The expansion of medical student numbers in the United Kingdom: Medical Schools Council position paper October 2021 Oct 2021. https://www.medschools.ac.uk/media/2899/the-expansion-ofmedical-student-numbers-in-the-united-kingdom-msc-position-paper-october-2021.pdf

3 Royal College of Psychiatrists. Double the number of medical school places to stop mental health services imploding. 27 Sep 2019.

https://www.rcpsych.ac.uk/news-and-features/latest-news/detail/2019/09/27/double-the-number-of-medical-school-places-to-stopmental-health-services-imploding

4 Rimmer A. UK medical school places must double, says Royal College of Physicians. BMJ2018;361:k2781. doi: 10.1136/bmj.k2781 pmid: 29941479

This article is made freely available for use in accordance with BMJ's website terms and conditions for the duration of the covid-19 pandemic or until otherwise determined by BMJ. You may use, download and print the article for any lawful, non-commercial purpose (including text and data mining) provided that all copyright notices and trade marks are retained. 